\title{
Increased C5a receptor expression in sepsis
}

\author{
Niels C. Riedemann, ${ }^{1}$ Ren-Feng Guo, ${ }^{1}$ Thomas A. Neff, ${ }^{1}$ Ines J. Laudes, ${ }^{1}$ Katie A. Keller, ${ }^{1}$ \\ Vidya J. Sarma, ${ }^{1}$ Maciej M. Markiewski, ${ }^{2}$ Dimitrios Mastellos, ${ }^{2}$ Christoph W. Strey, ${ }^{2}$ \\ Carl L. Pierson, ${ }^{1}$ John D. Lambris, ${ }^{2}$ Firas S. Zetoune, ${ }^{1}$ and Peter A. Ward ${ }^{1}$ \\ ${ }^{1}$ Department of Pathology, University of Michigan Medical School, Ann Arbor, Michigan, USA \\ ${ }^{2}$ Department of Pathology and Laboratory Medicine, University of Pennsylvania, Philadelphia, Pennsylvania, USA
}

\begin{abstract}
Excessive production of the complement activation product $\mathrm{C} 5 \mathrm{a}$ appears to be harmful during the development of sepsis in rodents. Little is known about the role of the C5a receptor $(\mathrm{C5aR})$ and its presence in different organs during sepsis. Using the cecal ligation/puncture (CLP) model in mice, we show here that $\mathrm{C5aR}$ immunoreactivity was strikingly increased in lung, liver, kidney, and heart early in sepsis in both control and neutrophil-depleted mice. C5aR mRNA expression in these organs was also significantly increased during sepsis. Immunohistochemical analysis revealed patterns of increased C5aR expression in parenchymal cells in all four organs following CLP. Mice injected at the start of CLP with a blocking IgG to C5aR $(\alpha \mathrm{C} 5 \mathrm{aR})$ showed dramatically improved survival when compared with animals receiving nonspecific IgG, as did mice injected with $\alpha \mathrm{C} 5 \mathrm{a}$. In $\alpha \mathrm{C} 5 \mathrm{aR}$-treated mice, serum levels of IL- 6 and TNF- $\alpha$ and bacterial counts in various organs were significantly reduced during CLP when compared with control CLP animals. These studies demonstrate for the first time that C5aR is upregulated in lung, liver, kidney, and heart during the early phases of sepsis and that blockade of C5aR is highly protective from the lethal outcome of sepsis.
\end{abstract}

J. Clin. Invest. 110:101-108 (2002). doi:10.1172/JCI200215409.

\section{Introduction}

In the early phases of sepsis, the complement activation product $\mathrm{C} 5 \mathrm{a}$ has been shown to play an important inflammatory role in rodents following cecal ligation and puncture (CLP) or subsequent to infusion of LPS $(1-5)$. Besides its strong chemotactic activity, other effects of C5a are known: release from phagocytic cells of granular enzymes, production in neutrophils of superoxide anion, histamine release from mast cells, vasodilatation, increased vascular permeability, smooth muscle contraction, and induction of thymocyte apoptosis during sepsis $(3,6-10)$. The responses to $\mathrm{C} 5 \mathrm{a}$ are mediated by a pertussis toxin-sensitive $\mathrm{G}$ protein-linked seven-transmembrane $\mathrm{C} 5 \mathrm{a}$ receptor (C5aR), which belongs to the superfamily of rhodopsin-type receptors $(11,12)$. Originally, C5aR was considered to be confined to myeloid cells (13). In recent years $\mathrm{C} 5 \mathrm{aR}$ has been shown to be present on a variety of cells in many different organs (liver, kidney, lungs, brain) (14-19) and on T cells (20).

Received for publication March 7, 2002, and accepted in revised form May 21, 2002.

Address correspondence to: Peter A. Ward, Department of Pathology, University of Michigan Medical School, 1301 Catherine Road, Ann Arbor, Michigan 48109-0602, USA. Phone: (734) 763-6384; Fax: (734) 763-4782;

E-mail: pward@umich.edu.

Conflict of interest: No conflict of interest has been declared.

Nonstandard abbreviations used: $\mathrm{C} 5 \mathrm{a}$ receptor $(\mathrm{C} 5 \mathrm{aR})$; cecal ligation/puncture (CLP); anti-C5aR $(\alpha \mathrm{C} 5 \mathrm{aR})$;

Dulbecco's phosphate-buffered saline (DPBS);

C5aR antagonist (C5aRa); ${ }^{125}$ I-labeled anti-mouse

C5aR IgG (125I- $\alpha \mathrm{C} 5 \mathrm{aR})$.
Excessive production of C5a during sepsis is associated with "deactivation" of blood neutrophils, resulting in loss of the respiratory burst and incapacitation of the vital oxygen-dependent pathway for killing of phagocytized bacteria (1). Given the importance of C5a during sepsis in rodents, the role of C5aR in sepsis would be predicted to be important, but it has not yet been demonstrated. Furthermore, little is known about the functional importance of $\mathrm{C} 5 \mathrm{aR}$ on nonmyeloid cells. Therefore, we investigated $\mathrm{C} 5 \mathrm{aR}$ content in lung, liver, kidney, and heart, before and during the early period of sepsis, using in vivo binding studies with ${ }^{125}$ I-antibody against mouse C5aR, RT-PCR analysis for mRNA of C5aR, and immunohistochemical staining of tissue sections. In addition, we investigated in CLP mice the effects of anti -C5aR $(\alpha \mathrm{C} 5 \mathrm{aR})$ on cytokine content in the serum and on bacterial colony counts in various organs. The data to be presented show that $\mathrm{C} 5 \mathrm{aR}$ is markedly upregulated during sepsis and that its blockade dramatically improves survival rates in sepsis, reduces cytokine serum levels, and greatly diminishes bacterial content in organs.
Methods
Peptide synthesis and production of $\alpha \mathrm{C} 5 \mathrm{aR}$ antibodies. A 37-amino acid peptide spanning the $\mathrm{N}$-terminus of the mouse C5aR and one extra cysteine (MDPIDNSS- FEINYDHYGTMDPNIPADGIHLPKRQPGDC) was synthesized using an Applied Biosystems (Foster City, California, USA) 430A peptide synthesizer as previ- ously described (21). The peptide was then coupled to keyhole limpet hemocyanin by the glutaraldehyde method and used for the immunization of rabbits and 
the production of immunoreactive antisera. The antipeptide specific antibody was purified by affinity chromatography using the synthetic peptide coupled to cyanogen bromide-activated Sepharose 4B (Pharmacia Biotech Inc., Piscataway, New Jersey, USA).

Production of $\alpha \mathrm{C} 5$ a antibody. The C-terminal end (amino acid residues 58-77) of the rat C5a molecule was chosen as described previously (5). The peptide was coupled to keyhole limpet hemocyanin (see above) and then used for the immunization of goats and the production of antisera. The anti-peptide specific antibody was affinity purified. Its cross-reactivity with recombinant mouse $\mathrm{C} 5 \mathrm{a}$ was confirmed in Western blots. Initial in vivo activity of this antibody was confirmed by the finding of reduced IgG immune complex-induced lung injury in mice when compared with control IgG-injected animals (data not shown).

Cloning and expression of mouse C5a. Total RNA was isolated from liver tissue from normal mice using the guanidine isothiocyanate method. The mouse C5a sequence was subcloned into $\mathrm{PET} 15 \mathrm{~b}$ expression vector (Novagen, Madison, Wisconsin, USA) using the following primers: $5^{\prime}$-GTG TCG CGA GTC AGC CAT ATG AAC CTG CAT CTC CTA-3' (sense, NdeI site underlined) and 5'-GTC ACA TCG CGA CAC GGA TCC TCA CCT TCC CAG TTG GAC-3' (antisense, BamHI site underlined). After expression of mouse C5a in BL21 (DE3) pLysS cells (Novagen), the recombinant protein was purified over a $\mathrm{Ni}^{++}$column and dialyzed with a tubing system (Pierce Chemical Co., Rockford, Illinois, USA). Biological activity of C5a was confirmed by conducting chemotaxis experiments with mouse neutrophils.

Experimental CLP-induced sepsis and organ preparation. Seven- or eight-week-old specific pathogen-free male $\mathrm{BALB} / \mathrm{c}$ mice (The Jackson Laboratory, Bar Harbor, Maine, USA) were used for all studies. Anesthesia was achieved by intraperitoneal injection of a Ketamine/Xylazine/Dulbecco's phosphate-buffered saline (DPBS) solution $(11 \mu \mathrm{l} / \mathrm{g}$ body weight), for which $1 \mathrm{ml}$ of Ketamine containing 9\% Xylazine was diluted with $7 \mathrm{ml}$ of DPBS. In the CLP model, approximately twothirds of the cecum was ligated through a $1.5-\mathrm{cm}$ abdominal midline incision. The ligated part of the cecum was punctured through and through with a 21gauge needle. After repositioning of the bowel, the abdomen was closed in layers, using a 4.0 surgical suture (Ethicon Inc., Somerville, New Jersey, USA) and metallic clips. Sham-operated animals underwent the same procedure without ligation or puncture of the cecum. For animal sacrifice, the inferior vena cava was incised and approximately $600 \mu \mathrm{l}$ blood withdrawn. The chest was then opened, and the pulmonary artery was slowly perfused with $40 \mathrm{ml}$ DPBS, the perfusion liquid being allowed to leak out of the open inferior vena cava after perfusion. Perfusion quality was optically controlled by observing the organ color change (to white) as the blood was completely removed. Thereafter, organs were removed for radioactivity analysis or snap-frozen for RT-PCR experiments and immunohis- tochemical staining. In lungs, bronchoalveolar lavage was also performed with a total volume of $3 \mathrm{ml}$.

In vivo binding studies. Polyclonal rabbit anti-mouse C5aR IgG that was affinity-purified or whole rabbit IgG (Jackson ImmunoResearch Laboratories Inc., West Grove, Pennsylvania, USA) was labeled with ${ }^{125}$ I, using the chloramine method, as described elsewhere (22). This protocol allowed gentle oxidation. The same method was used for labeling of recombinant mouse $\mathrm{C} 5 \mathrm{a}$. For the binding studies, sepsis was induced via CLP, and animals were sacrificed 3, 6, and 12 hours thereafter. Organ radioactivity was compared to that in sham-operated control animals. One hundred nanograms of ${ }^{125}$ I-labeled anti-mouse C5aR IgG ( ${ }^{125} \mathrm{I}-$ $\alpha \mathrm{C} 5 \mathrm{aR})$ together with $2 \mu \mathrm{g}$ nonlabeled antibody as carrier in a total volume of $200 \mu \mathrm{l}$ DPBS was administered intravenously 15 minutes before sacrifice of the animals. For binding studies with ${ }^{125}$ I-labeled mouse C5a, $100 \mathrm{ng}$ of ${ }^{125} \mathrm{I}-\mathrm{C} 5 \mathrm{a}$ together with $2 \mu \mathrm{g}$ nonlabeled C5a in $200 \mu \mathrm{l}$ DPBS was injected intravenously 10 minutes before sacrificing the animals. Two hundred microliters of blood were drawn from the abdominal caval vein to determine the amount of radioactivity in the blood 15 minutes after injection of ${ }^{125} \mathrm{I}-\alpha \mathrm{C} 5 \mathrm{aR}$ and 10 minutes after injection of ${ }^{125} \mathrm{I}-\mathrm{C} 5 \mathrm{a}$. Organs were then thoroughly flushed with DPBS and then harvested (as described above) and weighed. Radioactivity was measured in a gamma counter (1261 Multi- $\gamma$; Wallac Co., Gaithersburg, Maryland, USA). Data were expressed as cpm per g tissue, divided by the cpm in $100 \mu \mathrm{l}$ blood sample for each individual animal. Similar experiments were conducted, using neutrophil-depleted mice as controls. Neutrophil depletion was achieved using intraperitoneal injection of rabbit anti-mouse polymorphonuclear neutrophil IgG (Accurate Chemical \& Scientific Corp., Westbury, New York, USA) 18 hours before induction of CLP, according to the manufacturer's instructions.

Isolation of mouse neutrophils and in vitro binding studies. For isolation of neutrophils, 8-week-old BALB/c mice were injected intraperitoneally with $3 \mathrm{ml}$ of $2.4 \%$ thioglycollate solution (Difco Laboratories, Detroit, Michigan, USA) for 5 hours. Mice were then sacrificed, and a $1-\mathrm{cm}^{2}$ patch of skin was dissected from the abdominal muscles. $3 \times 10 \mathrm{ml}$ of DPBS was injected intraperitoneally, and the peritoneal lavage fluid was collected and kept at $4^{\circ} \mathrm{C}$. Neutrophils were then counted using a light microscope, spun down at 700 $g$ for 10 minutes, and suspended in HBSS containing 1\% BSA (Sigma Chemical Co., St. Louis, Missouri, USA) for 40 minutes to block unspecific binding. Neutrophils were then spun down and suspended in binding buffer (HBSS, $0.1 \%$ BSA) at a final concentration of $2 \times 10^{7}$ cells $/ \mathrm{ml}$ and incubated for $20 \mathrm{~min}-$ utes with whole rabbit IgG (control) or $\alpha \mathrm{C} 5 \mathrm{aR}$. Two hundred microliters of the cell suspensions were then incubated at $4^{\circ} \mathrm{C}$ for 20 minutes in the presence of ${ }^{125} \mathrm{I}-\mathrm{C} 5 \mathrm{a}$ (specific activity of $30-40 \mu \mathrm{Ci} / \mu \mathrm{g}$ ). Afterwards, the cell suspension was layered over $20 \%$ 
sucrose and sedimented by centrifugation $(11,000 \mathrm{~g})$ in a swinging bucket rotor for 2 minutes. After centrifugation, the tubes were frozen at $-80^{\circ} \mathrm{C}$ and the tips (containing the cell pellets) were cut off to determine the cell-bound ${ }^{125} \mathrm{I}-\mathrm{C} 5 \mathrm{a}$, using a gamma counter (1261 Multi- $\gamma$; Wallac Co.). Results were then expressed as cpm, as a function of the concentration of ${ }^{125} \mathrm{I}-\mathrm{C} 5 \mathrm{a}$, in order to establish the saturation curve.

$R N A$ isolation and detection of C $5 a R m R N A$ by semiquantitative RT-PCR. Organs from mice were obtained 0, 3, 6, and 12 hours after induction of CLP and prepared as described above. Total RNA was isolated with the Trizol method (Life Technologies Inc., Rockville, Maryland, USA) according to the manufacturer's instructions. Digestion of any contaminating DNA was achieved by treatment of samples with RQ1 RNase-Free DNase (Promega Corp., Madison, Wisconsin, USA).

Reverse transcription was performed with $5 \mu \mathrm{g}$ RNA using the Superscript II RNase $\mathrm{H}^{-}$Reverse Transcriptase (GIBCO BRL; Life Technologies Inc., Grand Island, New York, USA) according to the manufacturer's protocol. PCR was then performed with primers for C5aR: $5^{\prime}$ primer, $5^{\prime}$-TAT AGT CCT GCC CTC GCT CAT- $3^{\prime}$; and $3^{\prime}$ primer, $5^{\prime}$-TCA CCA CTT TGA GCG TCT TGG- $3^{\prime}$. The primers were designed for a 409-bp cDNA amplification in the middle region of the rat C5aR cDNA (positions 373-781). The primers for the "housekeeping" gene GAPDH were: $5^{\prime}$ primer, $5^{\prime}$-GCC TCG TCT CAT AGA CAA GAT G-3'; and $3^{\prime}$ primer, $5^{\prime}$-CAG TAG ACT CCA CGA CAT AC-3'. After a "hot-start" for 5 minutes at $94^{\circ} \mathrm{C}, 35$ cycles were used for amplification with a melting temperature of $94^{\circ} \mathrm{C}$, an annealing temperature of $60^{\circ} \mathrm{C}$, and an extending temperature of $72^{\circ} \mathrm{C}$, each for 1 minute, followed by a final extension at $72^{\circ} \mathrm{C}$ for 8 minutes. The RT-PCR product was confirmed by electrophoresis of samples in $1.2 \%$ agarose gel. Control experiments were performed with the samples; in these experiments we refrained from adding reverse transcriptase, in order to rule out contaminating DNA being responsible for any results. PCR was performed using different cycle numbers for C5aR and GAPDH primers, to assure that DNA was detected within the linear part of the amplifying curves for both primers. Results were presented in a semiquantitative manner. Immunobistochemical staining for C5aR. Organs from mice were flushed and harvested as described above at 0,6 , and 12 hours after CLP and snap-frozen in liquid nitrogen. For the lungs, bronchoalveolar lavage was performed as indicated, and the lungs were then inflated with $0.8 \mathrm{ml}$ of tissue-embedding solution (Tissue-Tek OCT compound; Fisher Scientific Co., Pittsburgh, Pennsylvania, USA) before freezing to prevent alveolar collapse. Six-micrometer tissue sections were first washed with PBS for 10 seconds and then fixed in methanol for 6 minutes. Next, the tissue sections were washed again in DPBS for 30 seconds and then incubated with $\alpha \mathrm{C} 5 \mathrm{aR}$ IgG in a dilution of $1: 100$ of the stock $(0.5 \mathrm{mg} / \mathrm{ml})$ in PBS for 2 hours. Thereafter, the tissue sections were washed for 2 minutes with DPBS before incubation with a 1:500 diluted peroxidase-conjugated goat anti-rabbit IgG for 30 minutes (Jackson ImmunoResearch Laboratories Inc.). After washing with PBS for 2 minutes, the sections were stained using the AEC vector staining kit (Vector Laboratories Inc., Burlingame, California, USA). Counterstaining was achieved with hematoxylin for 30 seconds. Tissue sections were fixed and cover slides were mounted with Permount medium (Fisher Scientific Co.). Staining was documented using light microscopy and digital imaging.

Detection of IL-6 and TNF- $\alpha$ in mouse serum by ELISA. Blood was drawn from $\alpha \mathrm{C} 5 \mathrm{aR}$ and control IgG-injected mice at 6 and 18 hours after CLP and was allowed to clot on ice for 2 hours before serum was obtained by centrifugation. Serum samples were then analyzed for IL- 6 and TNF- $\alpha$ content using ELISA kits (BioSource International Inc., Camarillo, California, USA) according to the manufacturer's instructions.

Bacterial counts in organs from CLP animals. Eighteen hours after CLP, lungs, livers, and kidneys were isolated from $\alpha \mathrm{C} 5 \mathrm{aR}$ and control IgG-injected mice. Five milliliters $70 \%$ ethanol was injected in the peritoneal cavity and left for 1.5 minutes prior to organ removal. Afterward, the liver, kidneys, and lungs were excised in a sterile manner and washed in a 70\% ethanol bath for 20 seconds to avoid surface bacterial contamination. Each organ was then manually homogenized in $3 \mathrm{ml}$ sterile $0.9 \% \mathrm{NaCl}$. Then, $2 \mathrm{ml}$ of enriched brain-heart infusion was added. Samples were then plated on $5 \%$ sheep blood agar or anaerobic blood agar and incubated for 48 hours at $35^{\circ} \mathrm{C}$ under aerobic and anaerobic conditions. CFUs were then determined in all plates and multiplied by the dilution factor. Data are presented as CFUs per $100 \mu \mathrm{l}$ of nondiluted tissue homogenate.

\section{Results}

Increased in vivo organ binding of ${ }^{125} I-\alpha C 5 a R$ during $C L P$ induced sepsis. To evaluate changes in $\mathrm{C} 5 \mathrm{aR}$ expression during sepsis, ${ }^{125} \mathrm{I}-\alpha \mathrm{C} 5 \mathrm{aR}(1.6 \mu \mathrm{Ci})$ was injected intravenously into mice $0,3,6$, and 12 hours after CLP and 15 minutes before sacrificing the animals. The antibody concentration was based on results from preliminary experiments (data not shown). For control animals, an equivalent amount of ${ }^{125} \mathrm{I}$-normal rabbit $\mathrm{IgG}\left({ }^{125} \mathrm{I}-\mathrm{IgG}\right)$ was administered 0,6 , and 12 hours after CLP as described above. Figure 1 summarizes the results of the binding studies. Figure 1a shows the results of ${ }^{125} \mathrm{I}-$ $\alpha \mathrm{C} 5 \mathrm{aR}$ binding in lung, liver, kidney, and heart at the various time points after CLP. In each of the organs, ${ }^{125} \mathrm{I}-$ $\alpha C 5 a R$ binding was significantly increased in the early phases of sepsis ( 3 and 6 hours) when compared with the values from animals obtained at time 0 . In lungs, a steep increase in binding of ${ }^{125} \mathrm{I}-\alpha \mathrm{C} 5 \mathrm{aR}$ occurred 6 hours after CLP; by 12 hours the increase was clearly reduced. In liver and kidney, significantly increased binding occurred by 3 hours, with peak binding at 6 hours. In heart, there was a continuous increase in ${ }^{125} \mathrm{I}$ $\alpha \mathrm{C} 5 \mathrm{aR}$ binding up to 12 hours after induction of CLP. 


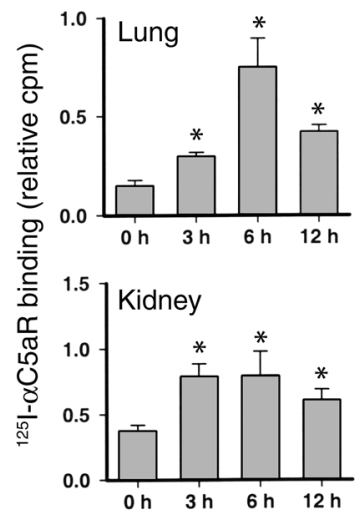

b

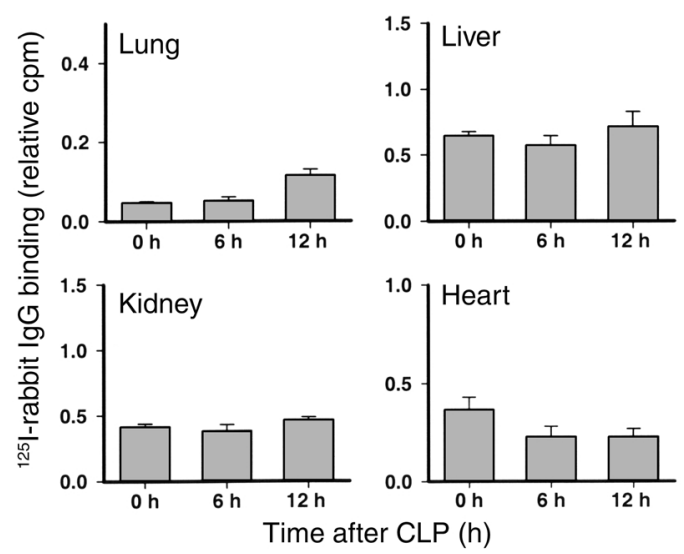

Figure $1 \mathrm{~b}$ shows binding results from ${ }^{125} \mathrm{I}$-IgG-injected mice. No significant changes in ${ }^{125} \mathrm{I}-\mathrm{IgG}$ binding in any organ could be observed 6 and 12 hours after CLP when compared with binding at 0 hours. Interestingly, in heart, ${ }^{125} \mathrm{I}$-IgG binding seemed to be slightly decreased 6 and 12 hours after CLP, when compared with the 0 -hour control groups.

Even though organs were extensively flushed to remove residual blood, we also conducted experiments in neutrophil-depleted animals at 0 and 6 hours after CLP in order to assess whether intravascular neutrophils were responsible for the observed increase in in vivo binding of ${ }^{125} \mathrm{I}-\alpha \mathrm{C} 5 \mathrm{aR}$. Figure 2 demonstrates significantly increased ${ }^{125} \mathrm{I}-\alpha \mathrm{C} 5 \mathrm{aR}$ binding in all four organs in neutrophil-depleted mice 6 hours after CLP. The increase was comparable to that found in liver, kidney, and heart in neutrophil-intact mice. In lungs, the increase in binding was less prominent in neutrophil-depleted CLP mice, when compared with neutrophil-intact animals. Accordingly, it is possible in the lung that full C5aR upregulation is dependent on neutrophil presence.

Inbibition of ${ }^{125} \mathrm{I}-\mathrm{C} 5 \mathrm{a}$ binding by $\alpha \mathrm{C} 5 \mathrm{aR}$. Binding experiments with ${ }^{125} \mathrm{I}$-mouse $\mathrm{C} 5 \mathrm{a}$ were conducted in vitro and in vivo to assess the effects of $\alpha \mathrm{C} 5 \mathrm{aR}$ to reduce binding of C5a. Figure 3 summarizes the results of these experiments. In Figure 3a, peritoneal mouse neutrophils were isolated and preincubated with either irrelevant rabbit IgG as control or $\alpha \mathrm{C} 5 \mathrm{aR} \operatorname{IgG}(1$ or $10 \mu \mathrm{g})$ for $20 \mathrm{~min}$ utes. Afterward, binding of $1 \mathrm{nM}{ }^{125}$ I-mouse C5a

\section{Figure 1}

(a) In vivo binding of ${ }^{125} \mathrm{I}-\alpha \mathrm{C} 5 \mathrm{aR}$ to organs $0,3,6$, and 12 hours after CLP. Binding is expressed as the ratio of cpm per g organ to cpm in $100 \mu \mathrm{l}$ blood from each animal, obtained 15 minutes after intravenous injection of ${ }^{125} \mathrm{I}-\alpha \mathrm{C} 5 \mathrm{aR}$. (b) In vivo binding of ${ }^{125}$ I-labeled rabbit IgG to similar organs expressed similarly to the data in $\mathbf{a}$. Data are representative of three to six animals for each time point. ${ }^{*}$ Statistical significance in treated groups when compared with control animals.

occurred for 20 minutes in the presence of the IgG preparations. A significant inhibition (60-73\%) of binding was found with $\alpha \mathrm{C} 5 \mathrm{aR}$ as a function of the amount of $\alpha \mathrm{C} 5 \mathrm{aR}$ present. The amount of unspecific binding was assessed in the presence of 100 -fold excess of nonlabeled C5a and measured with approximately $60 \mathrm{cpm}$ (subtracted in the $y$ axes). To further confirm inhibition of ${ }^{125} \mathrm{I}-\mathrm{C} 5 \mathrm{a}$ binding by $\alpha \mathrm{C} 5 \mathrm{aR}$, we conducted binding experiments in mice in vivo, 6 hours after CLP (Figure $3 \mathrm{~b})$. To block the binding of ${ }^{125} \mathrm{I}-\mathrm{C} 5 \mathrm{a}, \alpha \mathrm{C} 5 \mathrm{aR}$ was administered (as described above) 15 minutes in advance of the infusion of ${ }^{125} \mathrm{I}-\mathrm{C} 5 \mathrm{a} .{ }^{125} \mathrm{I}-\mathrm{C} 5 \mathrm{a}$ was then injected intravenously 10 minutes before sacrificing the animals. A prominent inhibition of ${ }^{125} \mathrm{I}-\mathrm{C} 5 \mathrm{a}$ binding was found in all four organs but did not reach statistical significant in lungs $(n=4)$. The results in Figure 3 demonstrate that $\alpha \mathrm{C} 5 \mathrm{aR}$ inhibits ${ }^{125} \mathrm{I}$-C5a binding significantly in vitro and in vivo.

Increased expression of $m R N A$ for $C 5 a R$ during CLPinduced sepsis in mice. To further extend the results from the in vivo binding experiments, we conducted RT-PCR experiments. Figure 4 summarizes the results of these experiments. In each of the four organs studied, there was an increase in the amount of mRNA for C5aR during the onset of CLP-induced sepsis, roughly correlat-

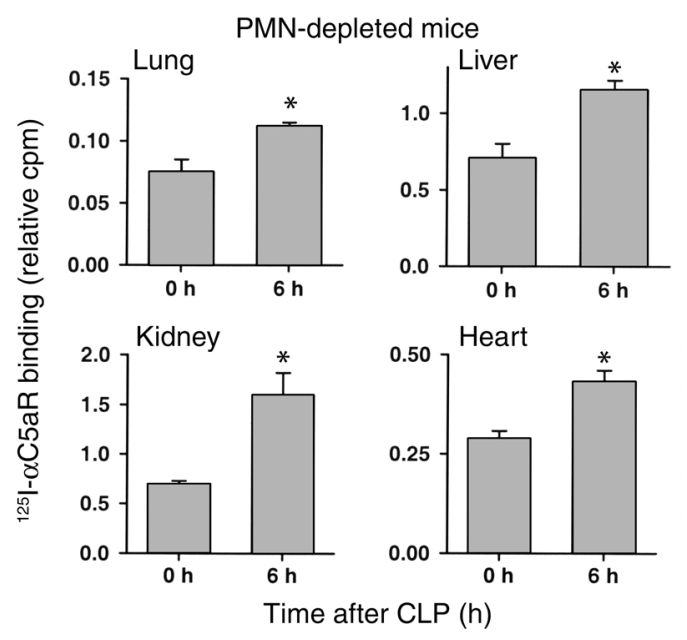

\section{Figure 2}

In vivo binding of ${ }^{125} \mathrm{I}-\alpha \mathrm{C} 5 \mathrm{aR}$ to various organs in neutrophil-depleted mice 0 and 6 hours after CLP. Binding is expressed as the ratio of cpm per g organ to cpm in $100 \mu \mathrm{l}$ blood from each animal, obtained 15 minutes after intravenous injection of ${ }^{125} \mathrm{I}-\alpha \mathrm{C} 5 \mathrm{aR}$. * Statistical significance in treated groups when compared with control animals. Data are representative of four to seven animals per group. PMN, polymorphonuclear neutrophil. 
a

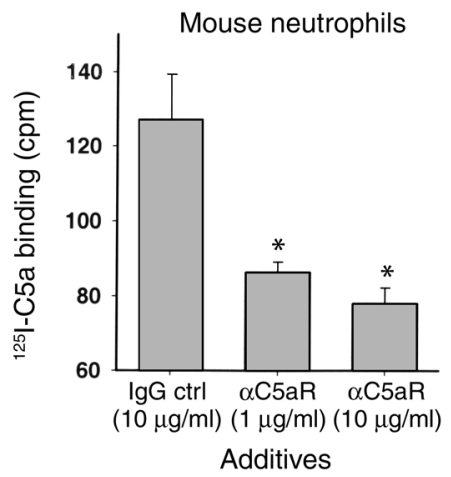

b
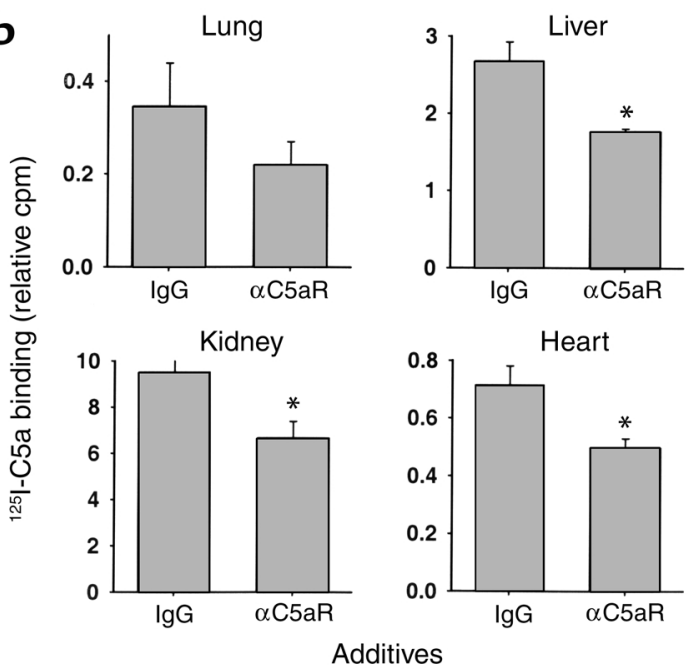

ing with increased organ binding of ${ }^{125} \mathrm{I}-\alpha \mathrm{C} 5 \mathrm{aR}$ (Figure 1). In the lung, an increase in mRNA for $\mathrm{C} 5 \mathrm{aR}$ in the semiquantitative RT-PCR was observed 6 hours after CLP (but not at 3 hours). In liver, kidney, and heart, increased levels of C5aR mRNA could be observed as early as 3 hours after onset of CLP. In liver, lung, and heart, the peak increase in C5aR mRNA expression occurred 6 hours after CLP, while in kidney a constant increase was found as long as 12 hours after CLP. The RT-PCR experiments suggested an increased gene expression for $\mathrm{C} 5 \mathrm{aR}$ early in sepsis, consistent with the observed increase in binding of ${ }^{125} \mathrm{I}-\alpha \mathrm{C} 5 \mathrm{aR}$ to the same organs. In data not shown, when small intestine and brain were evaluated 12 hours after CLP for increased binding of ${ }^{125} \mathrm{I}-\alpha \mathrm{C} 5 \mathrm{aR}$ or increased content of mRNA for $\mathrm{C} 5 \mathrm{aR}$, no increases were observed, suggesting that changes in C5aR mRNA are not global.

Immunobistochemical staining of lung, liver, kidney, and heart during sepsis. Based on the evidence of increased mRNA expression for $\mathrm{C} 5 \mathrm{aR}$ and increased ${ }^{125} \mathrm{I}-\alpha \mathrm{C} 5 \mathrm{aR}$ in vivo binding, we performed immunohistochemical staining of organs to address the question of where in the tissues increased $\mathrm{C} 5 \mathrm{aR}$ protein expression could be found. Figure 5 demonstrates immunohistochemical staining results in sections from lung, liver, kidney and heart obtained from control mice and CLP mice at 12 hours. In the lung, results revealed patterns of staining mainly in the bronchiolar epithelial cells. In liver, dif-

\section{Figure 3}

Inhibition of binding of ${ }^{125}$ I-labeled mouse C5a ( $\left.{ }^{125} \mathrm{I}-\mathrm{C} 5 \mathrm{a}\right)$ to peritoneal mouse neutrophils in vitro (a) and various organs in vivo (b) by $\alpha \mathrm{C} 5 \mathrm{aR}$. (a) Binding of ${ }^{125} \mathrm{I}-\mathrm{C} 5 \mathrm{a}$ is expressed as $\mathrm{cpm}$. Groups were treated (as indicated) for 20 minutes prior to binding of ${ }^{125} \mathrm{I}-\mathrm{C} 5 \mathrm{a}$. Data are representative of five independent experiments per condition. (b) Binding of ${ }^{125} \mathrm{I}-\mathrm{C} 5 \mathrm{a}$ is expressed as the ratio of cpm per $\mathrm{g}$ organ to $\mathrm{cpm}$ in $100 \mu \mathrm{l}$ blood from each animal ( $n=4$ per condition) obtained 10 minutes after intravenous injection of ${ }^{125} \mathrm{I}-\mathrm{C} 5 \mathrm{a}$ and 6 hours after CLP. $\alpha$ C5aR ( $6 \mu \mathrm{g} /$ mouse) or an equal amount of irrelevant rabbit IgG (control) was administered intravenously 15 minutes prior to ${ }^{125} \mathrm{I}-\mathrm{C} 5 \mathrm{a}$ infusion. ${ }^{*}$ Statistical significance in treated groups when compared with control animals. Ctrl, control.

fuse staining of the hepatocytes and sinusoidal cells was observed in contrast to staining of tissues in control mice. In the kidneys, CLP resulted in dramatically increased staining for $\mathrm{C} 5 \mathrm{aR}$ protein in proximal and distal tubular epithelial cells, but not in glomeruli. In the heart, 12 hours after CLP there was diffuse staining of myocytes. Accordingly, CLP causes a clear expression of $\mathrm{C} 5 \mathrm{aR}$ protein in organs in which we had already shown that mRNA for $\mathrm{C} 5 \mathrm{aR}$ and binding of ${ }^{125} \mathrm{I}-\alpha \mathrm{C} 5 \mathrm{aR}$ were increased.

Effects of $\alpha C 5$ aR or $\alpha C 5$ a IgG treatment in CLP mice. To investigate the roles of $\alpha \mathrm{C} 5 \mathrm{aR}$ and $\alpha \mathrm{C} 5 \mathrm{a}$ on survival rates in CLP-induced sepsis in mice, $20 \mu \mathrm{g} \alpha \mathrm{C} 5 \mathrm{aR} \mathrm{IgG}$ or $\alpha C 5 \mathrm{a}$ were injected intravenously in a volume of 200 $\mu \mathrm{l}$ DPBS into mice directly after induction of CLP, and, in the case of $\alpha \mathrm{C} 5 \mathrm{aR}$, also at 6 hours after CLP. In parallel, other CLP mice were given the same amount of normal rabbit IgG. Figure 6 demonstrates the results of this survival study. In the first 24 hours after induction of sepsis, in the group treated with anti-mouse C5a, only a single mouse died. The overall survival was $70 \%$ at day 7. In CLP mice treated with $\alpha \mathrm{C} 5 \mathrm{aR}$ at the
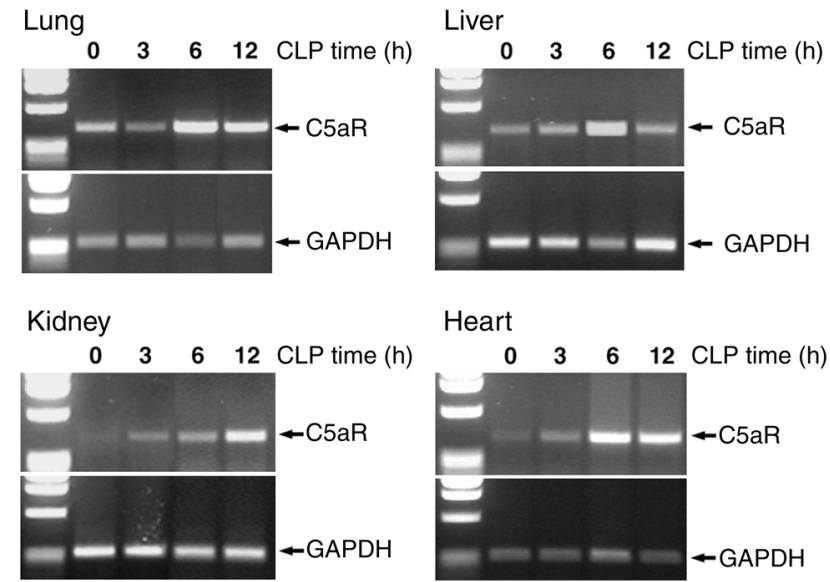

\section{Figure 4}

Semiquantitative RT-PCR for C5aR mRNA in lung, liver, kidney, and heart. RT-PCR was performed using RNA isolated $0,3,6$, and 12 hours after CLP. Approximately equal loading of the DNA product is demonstrated by expression of GAPDH mRNA (lower half of each panel). Results are representative of two independent and separate experiments for each group and time point. 


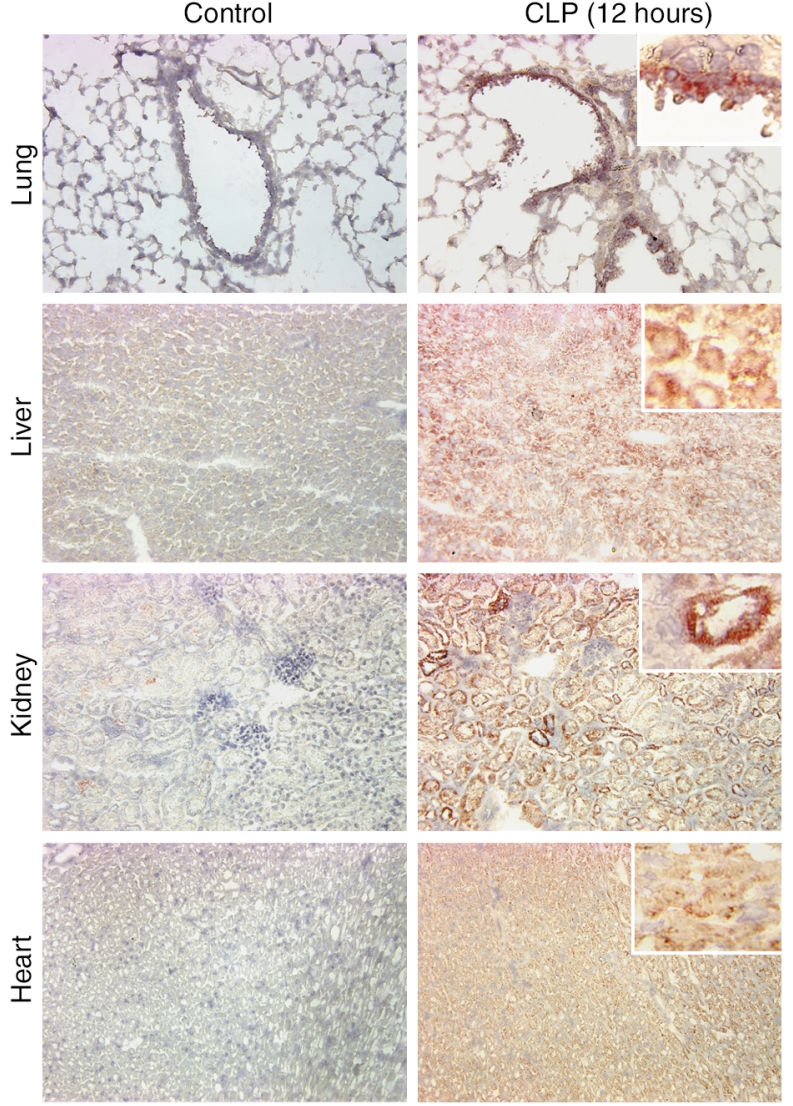

Figure 5

Immunohistochemical stains of organ sections for $\mathrm{C} 5 \mathrm{aR}$ from mice, as indicated in the text. Compared are staining results from organ sections from control animals (left panels) and from animals 12 hours after CLP (right panels). Results are representative of three to six stainings from two independent experiments per condition. Magnification, $\times 20$; insets in right panels, $\times 40$ (hematoxylin staining).

start of CLP, $24 \%$ of the animals died within the first 3 days. From this point onward, there were no additional deaths, with a 7-day overall survival of $76 \%$. In the CLP group treated with normal rabbit IgG, the survival curve dropped dramatically in the first 72 hours after CLP, revealing an overall survival of $0 \%$ by day 5 . In the CLP group receiving $\alpha \mathrm{C} 5 \mathrm{aR} 6$ hours after CLP, no beneficial effect could be observed, and all animals died, as in the control IgG-injected group. Therefore, treatment with $\alpha \mathrm{C} 5 \mathrm{a}$ or $\alpha \mathrm{C} 5 \mathrm{aR}$ antibody at the start of CLP dramatically increases the survival rate, suggesting the importance of $\mathrm{C} 5 \mathrm{a}$ and $\mathrm{C} 5 \mathrm{aR}$ in the lethal outcomes of CLP-induced sepsis in mice.

Effects of $\alpha \mathrm{C} 5 \mathrm{aR}$ antibody treatment on serum IL-6 and TNF- $\alpha$ levels and organ content of bacteria. To determine possible mechanisms responsible for the observed beneficial effects of $\alpha \mathrm{C5aR}$ treatment in septic mice, we measured IL- 6 and TNF- $\alpha$ serum levels in serum samples obtained 6 and 18 hours after CLP. Figure 7a summarizes the results, demonstrating significantly reduced IL- 6 levels at 6 and 18 hours and greatly reduced TNF- $\alpha$ levels 18 hours after CLP in $\alpha$ C5aR- treated animals, when compared with control IgG-injected mice. At 6 hours after CLP, none of the animals showed detectable TNF- $\alpha$ serum levels. These data suggest a significant linkage between $\mathrm{C} 5 \mathrm{aR}$ and serum levels of two cytokines that are negatively correlated with survival in sepsis. Since $\alpha \mathrm{C} 5 \mathrm{aR}$ significantly improved survival in CLP mice, we investigated bacterial CFUs in lung, liver, and kidney 18 hours after CLP. Figure $7 \mathrm{~b}$ demonstrates a significant reduction of aerobic bacterial counts in lungs and kidneys in the $\alpha \mathrm{C} 5 \mathrm{aR}-$ injected group when compared with control IgG-injected animals. In liver there was a similar tendency, but the error bars prevented statistical significance. This may be due to the liver being directly exposed to bacterial peritonitis of CLP. Bacterial counts for anaerobic cultures in the various organs showed patterns similar to those of the aerobic ones (data not shown).

\section{Discussion}

As mentioned above, C5a has been considered to be a harmful mediator during sepsis, presumably because of excessive production (1-5). Only recently as new blocking agents have become available (antibodies to $\mathrm{C} 5 \mathrm{aR}$ or antagonists to $\mathrm{C} 5 \mathrm{aR}$ ), more attention has been paid to the potential role of $\mathrm{C} 5 \mathrm{aR}$ in various organs $(14$, 16, 23-25). C5a is responsible for a broad variety of effects in different tissues, as described above. Unless levels of C5a are rigorously regulated in vivo, the effects of C5a may be harmful during the inflammatory response. The presence and the expression of $\mathrm{C} 5 \mathrm{aR}$ in organs has become an important focus.

Recently it has been shown that C5aR expression in the brain is increased following closed head injury (26). Immune complex-induced injury and tissue damage following ischemia/reperfusion have been reported to be attenuated by a C5aR antagonist (C5aRa) (27). Another C5aRa compound inhibits the reversed passive Arthus reaction in skin as well as endotoxic shock in rats $(28,29)$. In an experimental model of asthma and after airway instillation of LPS, C5aR and C3aR have been shown to be upregulated on bronchial epithelial cells and on smooth muscle cells of the airways (30). We were interested in evaluating C5aR expression in various organs during the development of sepsis in mice, since our recent work suggests in CLP rats that C5a is linked to adverse consequences (multiorgan failure and death), presumably related to interactions of C5a with C5aR. Besides lung, liver, kidney, and heart, we also investigated intestine, thyroid gland, and brain. In the latter three organs, no evidence of increased mRNA expression for $\mathrm{C} 5 \mathrm{aR}$ or in vivo binding of $\alpha \mathrm{C} 5 \mathrm{aR}$ IgG was found (data not shown) during the onset of sepsis. Therefore, we decided to focus on changes in lung, liver, kidney, and heart after CLP. We demonstrated increased in vivo binding of $\alpha \mathrm{C} 5 \mathrm{aR}$ and accompanying increased expression of mRNA for C5aR in these four organs after CLP-induced sepsis. In addition, immunohistochemical staining demonstrated that $\mathrm{C} 5 \mathrm{aR}$ was upregulated in bronchiolar epithelial cells and small 


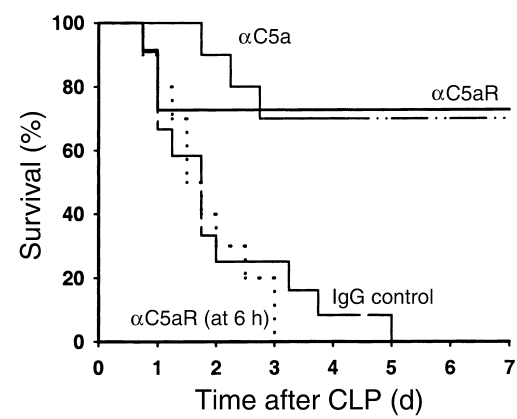

Figure 6

Survival study in CLP mice over 7 days. Mice were treated intravenously with $20 \mu \mathrm{g} \alpha \mathrm{C} 5 \mathrm{aR}(n=11), 20 \mu \mathrm{g} \alpha \mathrm{C} 5 \mathrm{a}(n=10)$, or $20 \mu \mathrm{g}$ rabbit IgG $(n=12)$, each being infused at the time of CLP. In another experiment, $20 \mu \mathrm{g} \alpha \mathrm{C} 5 \mathrm{aR}(n=10)$ was injected 6 hours after CLP.

vessels, hepatocytes, tubular epithelial cells of the kidney, and myocytes in the heart.

We have recently reported that $\mathrm{C} 5 \mathrm{a}$ binding to blood neutrophils in CLP rats is decreased and that the binding activity can be greatly improved by $\alpha \mathrm{C} 5 \mathrm{a}$ treatment (4), suggesting development of decreased surface C5aR on rat neutrophils during sepsis. Therefore, the question arises as to whether $\mathrm{C} 5 \mathrm{aR}$ on blood neutrophils during sepsis may be regulated differently from that demonstrated for the different organs in which increased binding of $\alpha \mathrm{C} 5 \mathrm{aR}$ was found in this study. The internalization of C5a $\bullet \mathrm{C} 5 \mathrm{aR}$ complexes on the surfaces of phagocytic cells is well known. We are currently investigating C5aR content on neutrophils during sepsis in rats. Preliminary data indicate the loss of C5aR on blood neutrophils after CLP (N.C. Riedemann et al., unpublished data), suggesting that $\mathrm{C} 5 \mathrm{aR}$ on blood neutrophils may be regulated differently from $\mathrm{C} 5 \mathrm{aR}$ in solid organs during sepsis. Our data suggest that $\mathrm{C} 5 \mathrm{aR}$ protein and $\mathrm{mRNA}$ are both upregulated in organs during sepsis. An additional possibility is that C5aR, during sepsis, undergoes a conformational change, which enhances its affinity for the antibody, but there is no direct evidence to support this possibility.
Even though treatment with antibodies to C5a greatly increases survival in CLP-induced sepsis in rats (1), blockade of the C5aR with specific antibody has not been previously assessed in experimental sepsis. The results with treatment of CLP mice with $\alpha$ C5aR IgG demonstrated markedly improved survival when mice were injected with $\alpha \mathrm{C} 5 \mathrm{aR}$ immediately after CLP. Delayed infusion (until 6 hours of sepsis) of $\alpha \mathrm{C} 5 \mathrm{aR}$ did not result in a beneficial outcome in sepsis, perhaps because of early increases in $\mathrm{C} 5 \mathrm{aR}$ in various organs. Our results demonstrate the dramatic effects of $\alpha \mathrm{C} 5 \mathrm{aR}$ treatment on serum levels of IL- 6 and TNF- $\alpha$ during sepsis (Figure 7a) and on bacterial CFU content in various organs (Figure 7b). These data suggest that blockade of $\mathrm{C} 5 \mathrm{aR}$ greatly attenuates the cytokine response. High IL-6 serum levels have been demonstrated to be predictive of poor outcomes in septic patients (31-33). The results in Figure $7 \mathrm{~b}$ also suggest that beneficial effects of $\alpha C 5$ aR treatment (reduced organ CFUs) may be explained by enhanced bacterial clearance, perhaps due to preservation of the neutrophil oxidative burst as in CLP rats treated with $\alpha \mathrm{C} 5 \mathrm{a}$ (4). It is also possible that sepsis-induced upregulation of $\mathrm{C} 5 \mathrm{aR}$ in organs renders these organs susceptible to harmful effects after contact with C5a, although this remains to be shown.

The biological significance of increased C5aR expression in different organs during sepsis remains to be defined. It might be noted that in CLP in rats, the liver, lungs, and kidneys become targets for development of multiorgan failure, and that interception of $\mathrm{C} 5 \mathrm{a}$ with $\alpha C 5$ areatly improves survival and dramatically reduces the intensity of multiorgan failure $(1,4)$. We have recently found that C5aR expression after CLP is increased in the rat thymus and is correlated with increased binding of C5a and induction of apoptosis (34).

The results of the current studies indicate that $\mathrm{C} 5 \mathrm{aR}$ expression is increased in lung, liver, kidney, and heart during CLP-induced sepsis in mice at the protein level as well as at the transcriptional level. Our results underscore the importance of increased C5aR expression during sepsis by demonstrating a significantly improved

\begin{abstract}
Figure 7
(a) ELISA measurements for IL- 6 and TNF- $\alpha$ serum levels at 6 and 18 hours after CLP-induced sepsis and in healthy control mice (normal). When used, $\alpha C 5 \mathrm{aR}$ treatment consisted of $20 \mu \mathrm{g} /$ mouse at the start of CLP, with a companion group treated with control IgG $(20 \mu \mathrm{g} /$ mouse $)$. (b) Content of aerobic bacteria in lung, liver, and kidney 18 hours after CLP-induced sepsis in mice. Compared groups were treated as described for a ( $n=4$ for all groups). * Statistically significant changes between $\alpha \mathrm{C5}$ aRand control IgG-treated CLP groups.
\end{abstract}
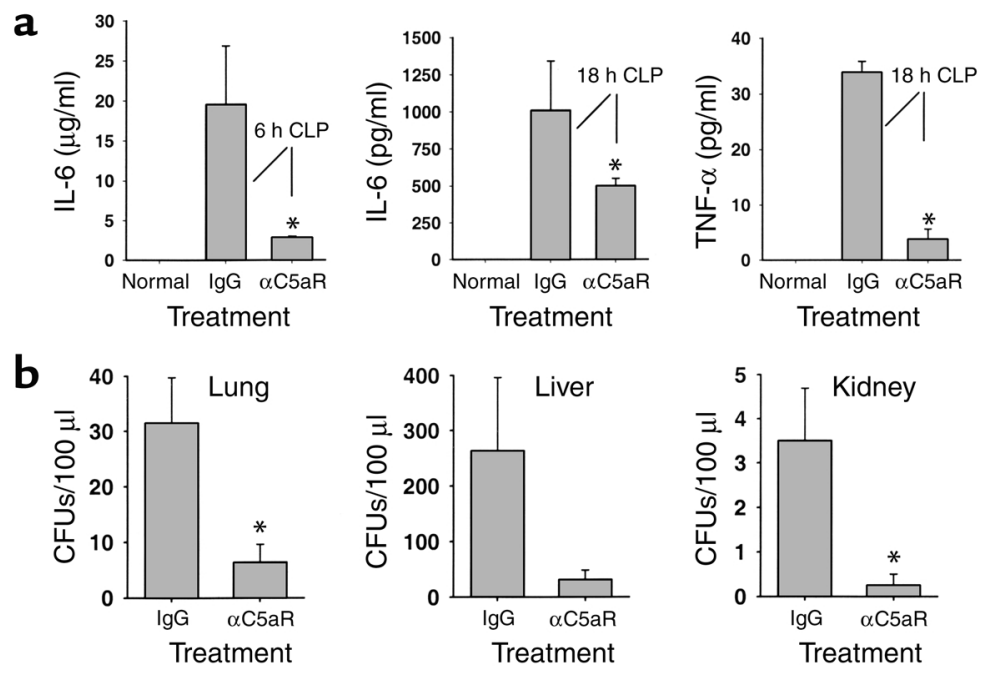

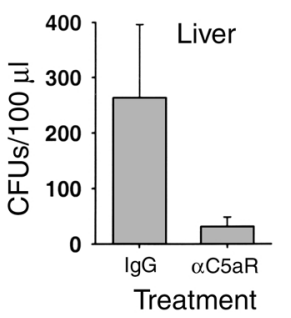

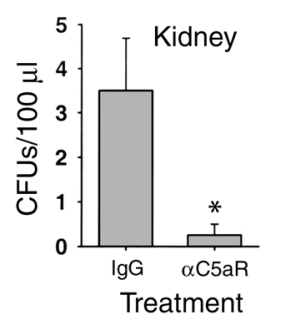


survival in CLP mice after C5aR blockade or with $\alpha \mathrm{C5}$ a. The functional relevance of increased C5aR expression in different organs during sepsis remains to be determined. Our findings suggest that the further investigation of compounds that intercept C5a or interfere with its ability to bind to C5aR is warranted.

\section{Acknowledgments}

This paper was supported by the following NIH National Heart, Lung, and Blood Institute grants: GM29507, HL-31963, GM-61656, and GM-62134.

1. Czermak, B.J., et al. 1999. Protective effects of C5a blockade in sepsis. Nat. Med. 5:788-792.

2. Smedegard, G., Cui, L.X., and Hugli, T.E. 1989. Endotoxin-induced shock in the rat. A role for C5a. Am. J. Pathol. 135:489-497.

3. Guo, R.F., et al. 2000. Protective effects of anti-C5a in sepsis-induced thymocyte apoptosis. J. Clin. Invest. 106:1271-1280.

4. Huber-Lang, M., et al. 2001. Role of C5a in multiorgan failure during sepsis. J. Immunol. 166:1193-1199.

5. Huber-Lang, M.S., et al. 2001. Protective effects of anti-C5a peptide antibodies in experimental sepsis. FASEB J. 15:568-570.

6. Cochrane, C.G., and Muller-Eberhard, H.J. 1968. The derivation of two distinct anaphylatoxin activities from the third and fifth components of human complement. J. Exp. Med. 127:371-386.

7. Goldstein, I.M., and Weissmann, G. 1974. Generation of C5-derived lysosomal enzyme-releasing activity (C5a) by lysates of leukocyte lysosomes. J. Immunol. 113:1583-1588.

8. Sacks, T., Moldow, C.F., Craddock, P.R., Bowers, T.K., and Jacob, H.S. 1978. Oxygen radicals mediate endothelial cell damage by complementstimulated granulocytes. An in vitro model of immune vascular damage. J. Clin. Invest. 61:1161-1167.

9. Schumacher, W.A., Fantone, J.C., Kunkel, S.E., Webb, R.C., and Lucchesi, B.R. 1991. The anaphylatoxins C3a and C5a are vasodilators in the canine coronary vasculature in vitro and in vivo. Agents Actions. 34:345-349.

10. Shin, H.S., Snyderman, R., Friedman, E., Mellors, A., and Mayer, M.M. 1968. Chemotactic and anaphylatoxic fragment cleaved from the fifth component of guinea pig complement. Science. 162:361-363.

11. Gerard, N.P., Hodges, M.K., Drazen, J.M., Weller, P.F., and Gerard, C. 1989. Characterization of a receptor for $\mathrm{C} 5 \mathrm{a}$ anaphylatoxin on human eosinophils. J. Biol. Chem. 264:1760-1766.

12. Gerard, N.P., and Gerard, C. 1991. The chemotactic receptor for human C5a anaphylatoxin. Nature. 349:614-617.

13. Chenoweth, D.E., and Hugli, T.E. 1978. Demonstration of specific C5a receptor on intact human polymorphonuclear leukocytes. Proc. Natl. Acad. Sci. USA. 75:3943-3947.

14. Zwirner, J., Fayyazi, A., and Gotze, O. 1999. Expression of the anaphylatoxin C5a receptor in non-myeloid cells. Mol. Immunol. 36:877-884.

15. Haviland, D.L., et al. 1995. Cellular expression of the C5a anaphylatoxin receptor (C5aR): demonstration of C5aR on nonmyeloid cells of the liver and lung. J. Immunol. 154:1861-1869.

16. Floreani, A.A., et al. 1998. Expression of receptors for C5a anaphylatoxin (CD88) on human bronchial epithelial cells: enhancement of C5a- mediated release of IL-8 upon exposure to cigarette smoke. J. Immunol. 160:5073-5081.

17. Schieferdecker, H.L., Schlaf, G., Koleva, M., Gotze, O., and Jungermann, K. 2000. Induction of functional anaphylatoxin C5a receptors on hepatocytes by in vivo treatment of rats with IL-6. J. Immunol. 164:5453-5458.

18. Wetsel, R.A. 1995. Expression of the complement C5a anaphylatoxin receptor (C5aR) on non-myeloid cells. Immunol. Lett. 44:183-187.

19. Gasque, P., Singhrao, S.K., Neal, J.W., Gotze, O., and Morgan, B.P. 1997. Expression of the receptor for complement C5a (CD88) is up-regulated on reactive astrocytes, microglia, and endothelial cells in the inflamed human central nervous system. Am. J. Pathol. 150:31-41.

20. Nataf, S., Davoust, N., Ames, R.S., and Barnum, S.R. 1999. Human T cells express the C5a receptor and are chemoattracted to C5a. J. Immunol. 162:4018-4023.

21. Becherer, J.D., and Lambris, J.D. 1988. Identification of the C3b receptor-binding domain in third component of complement. J. Biol. Chem. 263:14586-14591.

22. Bennett, G.L., and Horuk, R. 1997. Iodination of chemokines for use in receptor binding analysis. Methods Enzymol. 288:134-148.

23. Osaka, H., et al. 1999. Expression of C5a receptor in mouse brain: role in signal transduction and neurodegeneration. Neuroscience. 88:1073-1082.

24. Rothermel, E., Gotze, O., Zahn, S., and Schlaf, G. 2000. Analysis of the tissue distribution of the rat C5a receptor and inhibition of C5a-mediated effects through the use of two MoAbs. Scand. J. Immunol. 52:401-410.

25. Zahedi, R., et al. 2000. The C5a receptor is expressed by human renal proximal tubular epithelial cells. Clin. Exp. Immunol. 121:226-233.

26. Stahel, P.F., et al. 2000. Intracerebral complement C5a receptor (CD88) expression is regulated by TNF and lymphotoxin-alpha following closed head injury in mice. J. Neuroimmunol. 109:164-172.

27. Heller, T., et al. 1999. Selection of a C5a receptor antagonist from phage libraries attenuating the inflammatory response in immune complex disease and ischemia/reperfusion injury. J. Immunol. 163:985-994.

28. Strachan, A.J., Woodruff, T.M., Haaima, G., Fairlie, D.P., and Taylor, S.M. 2000. A new small molecule C5a receptor antagonist inhibits the reverse-passive Arthus reaction and endotoxic shock in rats. J. Immunol. 164:6560-6565.

29. Strachan, A.J., Shiels, I.A., Reid, R.C., Fairlie, D.P., and Taylor, S.M. 2001. Inhibition of immune-complex mediated dermal inflammation in rats following either oral or topical administration of a small molecule C5a receptor antagonist. Br. J. Pharmacol. 134:1778-1786.

30. Drouin, S.M., et al. 2001. Expression of the complement anaphylatoxin C3a and C5a receptors on bronchial epithelial and smooth muscle cells in models of sepsis and asthma. J. Immunol. 166:2025-2032.

31. Calandra, T., Gerain, J., Heumann, D., Baumgartner, J.D., and Glauser, M.P. 1991. High circulating levels of interleukin-6 in patients with septic shock: evolution during sepsis, prognostic value, and interplay with other cytokines. The Swiss-Dutch J5 Immunoglobulin Study Group. Am. J. Med. 91:23-29.

32. Casey, L.C., Balk, R.A., and Bone, R.C. 1993. Plasma cytokine and endotoxin levels correlate with survival in patients with the sepsis syndrome. Ann. Intern. Med. 119:771-778.

33. Damas, P., et al. 1992. Cytokine serum level during severe sepsis in human IL-6 as a marker of severity. Ann. Surg. 215:356-362.

34. Riedemann, N.C., et al. 2002. C5a receptor and thymocyte apoptosis in sepsis. FASEB J. 16:887-888. doi:10.1096/fj.02-0033fje. 